\title{
Orthodontic treatment of Skeletal Class II division 1 malocclusion : A case report
}

\author{
MW Ali ${ }^{1}$, MZ Hossain ${ }^{2}$, MM Zaki ${ }^{3}$
}

\begin{abstract}
:
Aim and objective of the present case report was to evaluate the management of skeletal Class II division 1 malocclusion in a 13 year old adolescent male patient with extraction of upper 1 st and lower 2 nd premolars. Clinical and cephalometric evaluation revealed skeletal Class II division 1 malocclusion with severe maxillary incisor proclination, convex profile, increased mandibular plane angle, incompetent lips, $14 \mathrm{~mm}$ overjet and deep overbite. After extraction of upper 1st and lower 2nd premolars, canine retraction was done by Class II elastics which was followed by retraction of severely proclined upper anterior teeth by judicious control of third order bend in rectangular stainless steel arch wire with "V" loop. Simultaneous alignment, leveling and correction of deep curve of Spee was done in lower arch. For anchorage management, intraoral anchorage with tip back \& toe in bends in stainless steel arch wire was satisfactory. Following treatment marked improvement in patient's smile, facial profile and lip competence were achieved and there was a remarkable increase in the patient's confidence and quality of life.
\end{abstract}

Keywords: Skeletal Class II division1 malocclusion, adolescent patient, Class II elastic, tip back and toe in bend.

\section{Introduction:}

Class II division 1 malocclusion is more prevalent than any type of malocclusion after Class I malocclusion in our country. 1,2 Over the last decade, increasing numbers of adults have become aware of orthodontic treatment and are demanding high quality treatment, in the shortest possible time with increased efficiency and reduced costs. ${ }^{3}$ Class II malocclusions can be treated by several means, according to the characteristics associated with the problem, such as anteroposterior discrepancy, age, and patient compliance. ${ }^{4}$ Methods include extraoral appliances, functional appliances and fixed appliances associated with Class II intermaxillary elastics. ${ }^{5}$ On the other hand, correction of Class II malocclusions in adolescent patients usually include extraoral orthopaedic appliances with selective removal of permanent teeth. The indications for extractions in orthodontic practice have historically been controversial. ${ }^{6-8}$ Premolars are probably the most commonly extracted teeth for orthodontic purposes as they are conveniently located between

1. Dr. Md. Wazed Ali, Assistant Professor \& Head, Dept. of Orthodontics, Dental Unit, Chittagong Medical College

2. Dr. Md. Zakir Hossain, Professor \& Head, Dept. of orthodontics, Dhaka Dental College.

3. Dr. Mahbub Zaki, Consultant, BSMMU.

Address of Correspondence: Dr. Md. Wazed Ali, Assistant Professor \& Head, Dept. of Orthodontics, Dental Unit, Chittagong Medical College
The anterior and posterior segments. Variations in extraction sequences including upper and lower first or second premolars have been recommended by different authors for a variety of reasons. ${ }^{9-14}$ For correction of Class II malocclusions in adolescent patients, extractions can involve 2 maxillary premolars ${ }^{15}$ or 2 maxillary and 2 mandibular premolars. ${ }^{16}$ It is usually not the skeletal characteristics of a Class II malocclusion that primarily determine whether it should be treated with 2 or 4 premolar extractions but, rather, the dentoalveolar characteristics.

The extraction of only 2 maxillary premolars is generally indicated when there is no crowding or cephalometric discrepancy in the mandibular arch. ${ }^{17,18}$ Extraction of 4 premolars is indicated primarily for crowding in the mandibular arch, a cephalometric discrepancy, or a combination of both, in growing patients. ${ }^{17-19}$ Recent studies have shown that patient satisfaction with camouflage treatment is similar to that achieved with surgical mandibular advancement. ${ }^{20}$

\section{Case Report}

\section{Pretreatment assessment :}

A 13 year old male reported to the Orthodontic Department at Dhaka Dental College \& Hospital with multiple complaints "my teeth stick out", "I am unable to close my lips" "I feel embarrassed when I laugh". Extra oral examination revealed a long symmetrical face, convex hard and soft tissue profile, lip trap and an acute nasolabial angle. The patient showed a good range of mandibular movements and no TMJ symptoms. Intra 
oral examination revealed that the patient had a full Class II molar and canine relationship, excessively proclined maxillary incisors with an overjet of $14 \mathrm{~mm}$, traumatic deep overbite and severely crowded lower arch. (Fig 1,2) Cephalometric examination revealed Class II skeletal relation with severe maxillary incisor proclination with vertical growth pattern (fig 1,2). Although the underlying sagittal jaw discrepancy was severe, the selective extraction of two $1^{\text {st }}$ premolar teeth in the upper arch and two $2^{\text {nd }}$ premolar teeth in lower arch was considered acceptable. Our treatment objective focused on the chief complaint of the patient, and the treatment plan was individualized based on the specific treatment goals.
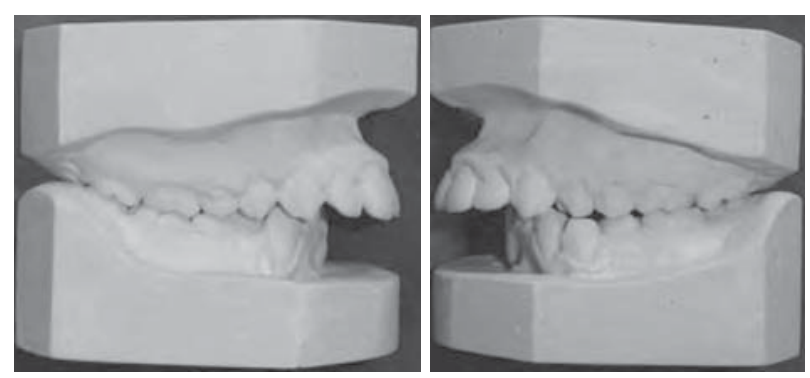

Figure 1: Pre treatment study model left \& right buccal view

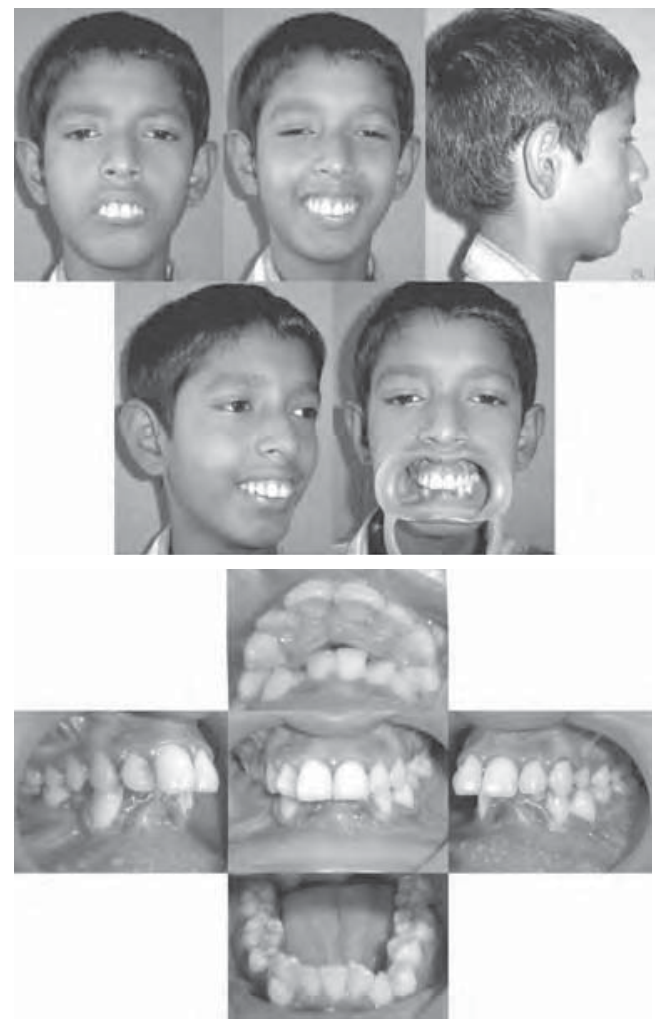

Figure 2. Pre treatment extra oral \& intra oral photographs

\section{Diagnosis:}

Skeletal Class II division 1 malocclusion with severe maxillary incisor proclination, convex profile, high mandibular plane angle, lip trap, incompetent lips, 14 $\mathrm{mm}$ overjet and traumatic deep overbite.

\section{Treatment objectives:}

1. Achieve lip competency

2. Develop an ideal overjet and overbite

3. Correct the anteroposterior relationship

4. Achieve occlusal intercuspation with a Class I canine and molar relationship

5. Improve the profile and facial esthetics

\section{Treatment plan:}

1. Extraction of maxillary first and mandibular second premolars.

2. Alignment \& leveling of upper and lower arches.

3. Correction of deep curve of Spee to reduce deep overbite.

4. Retraction of upper canines by class II elastics.

5. Upper arch contraction and use of intermaxillary elastics.

6. Final settling of the occlusion and arch coordination.

\section{Treatment Progress :}

The maxillary first and mandibular second premolars were extracted. The first molars were banded and the maxillary and mandibular teeth were bonded from premolar to premolar with a $0.018 \times 0.025$ standard edgewise brackets. Retractions of upper canines was done in 0.016 inch round stainless steel arch wire with stop loops and tip back and toe-in anchorage bends and use of class II elastics.
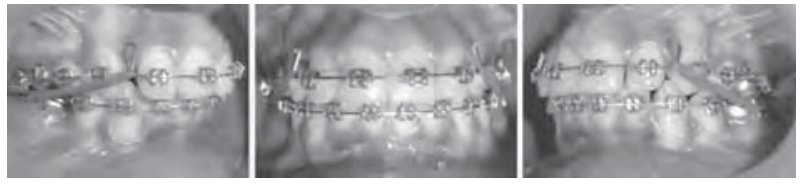

Figure 3. After Canine retraction, upper arch contraction with Class II elastics started (right buccal, frontal and left buccal view)

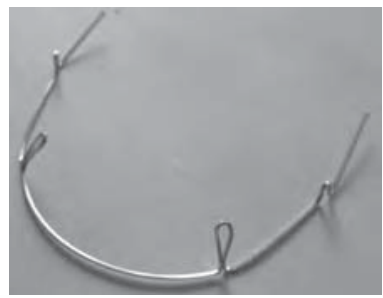

Figure 4. Rectangular (0.017 X 0.025) arch wire with " $V$ " loop for upper arch contraction 
Arch contraction and closure of extraction spaces in upper arch was done by rectangular(0.017 X 0.025 inch) Stainless Steel archwire with "V" loops with proper control of third order bend 'Torque'. (Fig. $3 \& 4$ ). Use of Class II elastics provide anchorage loss in the lower arch to establish class I molar relationship and anchorage reinforcement in the upper arch. Final settling of occlusion was done with proper interdigitation, inclination, angulation, ideal overjet and overbite. Debonded and retention was given by upper and lower Hawley's retainers. Patient was advised to follow up in retention period.

Post treatment assessment: Lip competency and a straight profile were achieved, improving the patient's facial appearance. A functional occlusion with normal overjet and overbite; class I canine and molar relationship was achieved(Fig.5,6,7,8\&9). Duration of the treatment was 21 months. The patient and his parent were very happy with complete satisfaction.
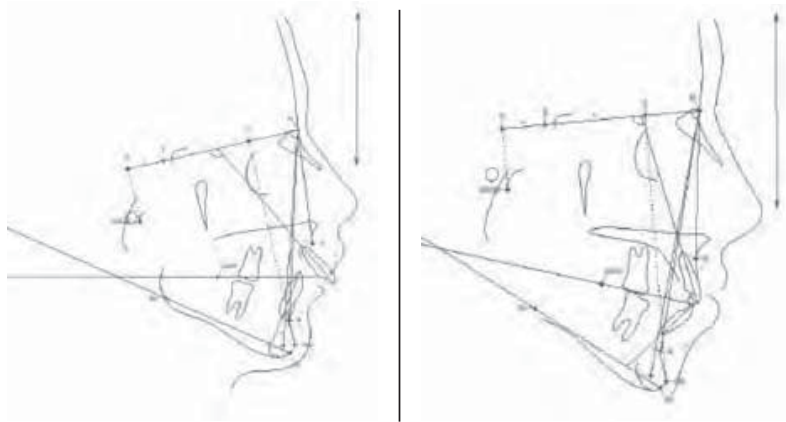

Figure 5. Pre and post treatment lateral Cephalogram Table

Table 1: Cephalometric Analysis

\begin{tabular}{|l|c|c|c|}
\hline Variables & $\begin{array}{c}\text { Reference } \\
\text { Measurements }\end{array}$ & $\begin{array}{c}\text { Pre } \\
\text { treatment }\end{array}$ & $\begin{array}{c}\text { Post } \\
\text { treatment }\end{array}$ \\
\hline SNA & 82 & 85 & 82.5 \\
\hline SNB & 80 & 74.5 & 77.5 \\
\hline ANB & 2 & 10.5 & 5 \\
\hline IIA & 130 & 120 & 130 \\
\hline U1-SN & 104 & 115 & 108 \\
\hline $\begin{array}{l}\text { GoGn to } \\
\text { SN }\end{array}$ & 32 & 36 & 35 \\
\hline
\end{tabular}

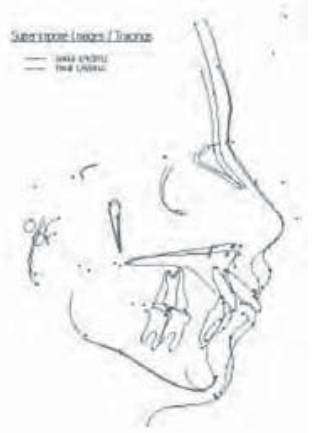

Figure 6. Superimposition of Cephalometric Tracing Pre Treatment (Black) Post Treatment (Blue)
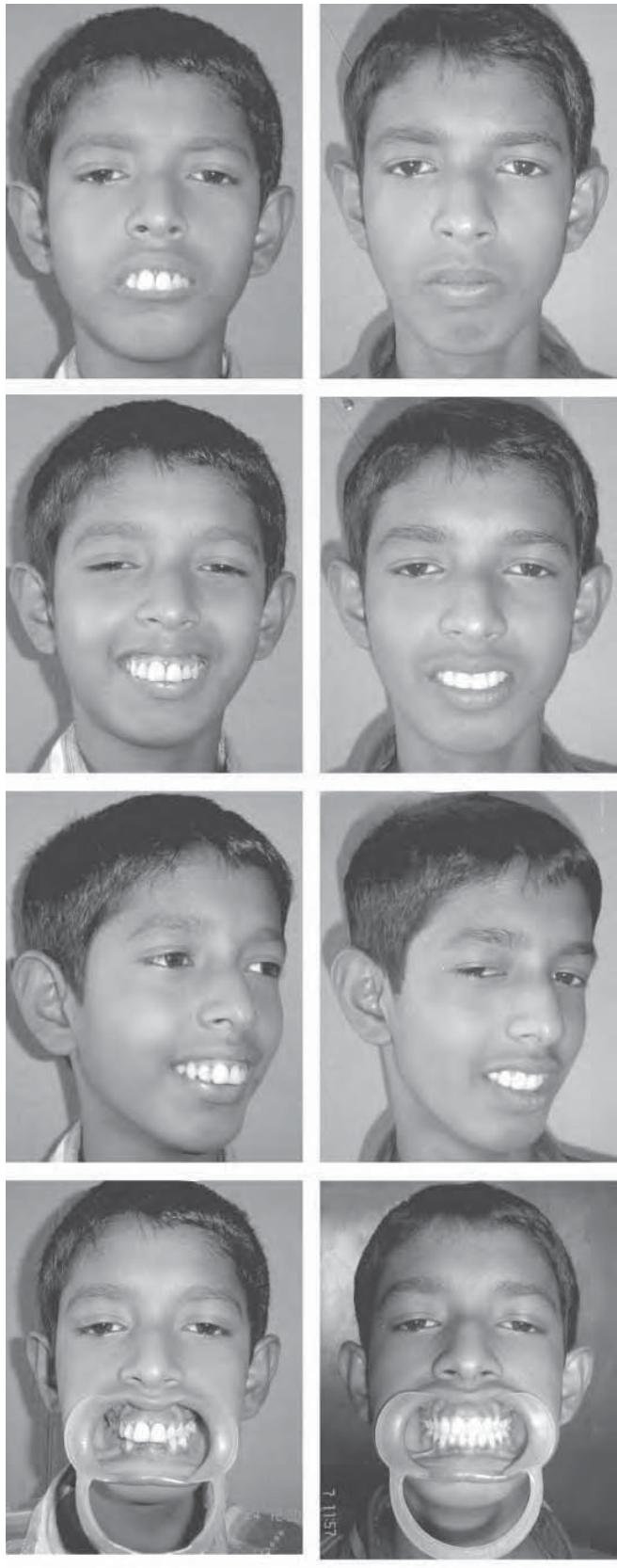

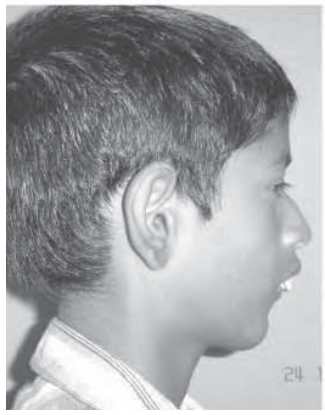

Pretreatment

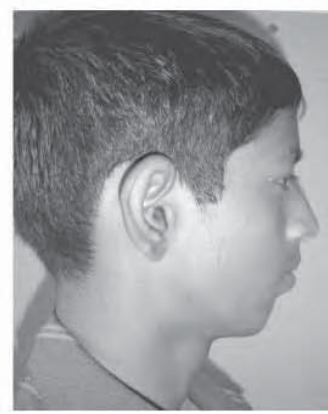

Post treatment
Figure 7. Pre \& post treatment extra oral photographs 

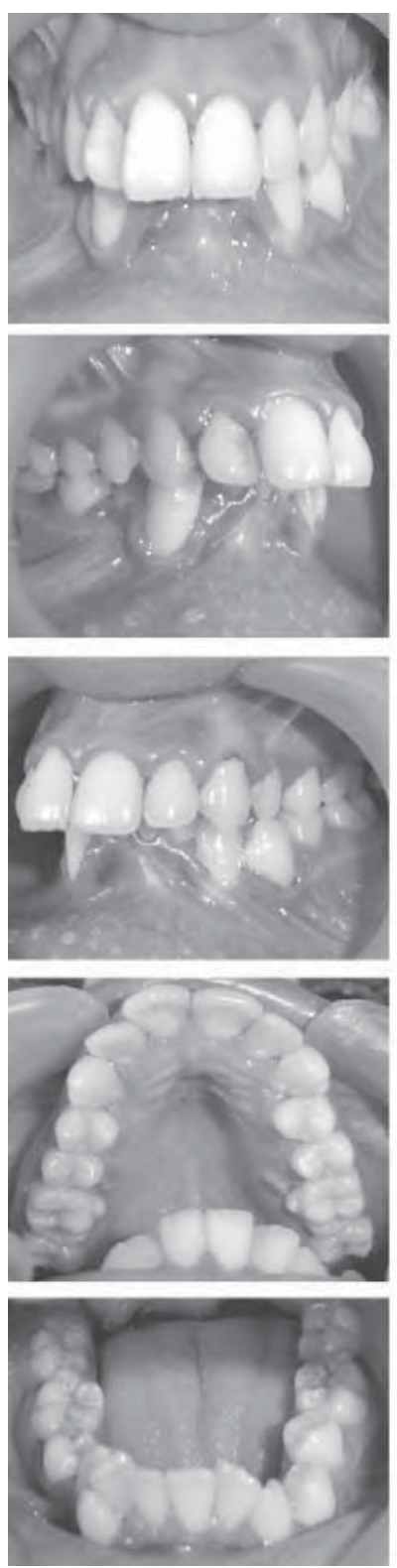

Pre treatment

Post treatment

Figure 8: Pre \& Post treatment intra oral photographs

\section{Post treatment follow up:}

In this case, skeletal correction was achieved by growth modification. This type of case is considered for long term retention \& follow up. After 4 years of follow up, patients aesthetic \& profile was excellent (Fig 9).
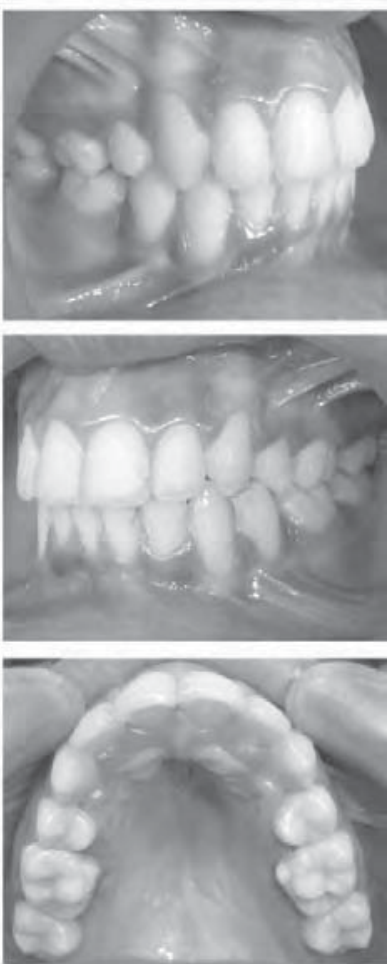
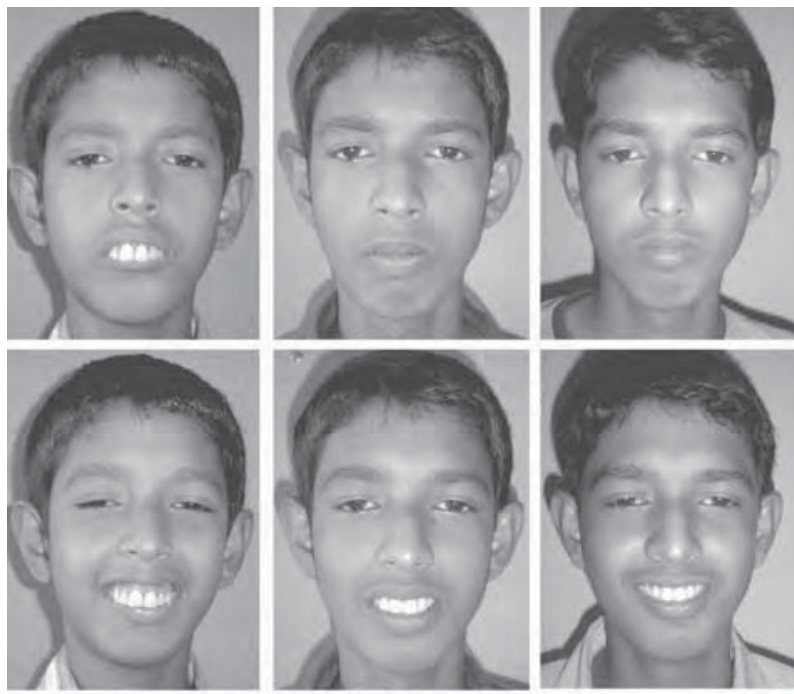

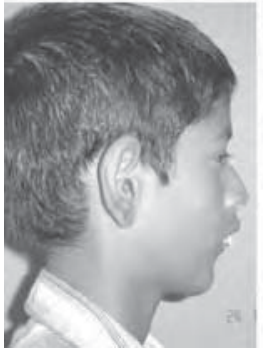

Pre treatment

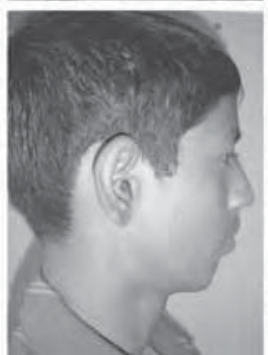

After Debonding

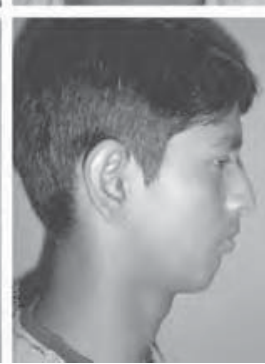

After 04 years
Figure 9: Excellent prognosis after 04 years of follow up

\section{Discussion:}

Patient had improved smile and profile after orthodontic treatment. Upper incisors were retracted to achieve normal incisor inclinations, overjet and overbite. Bilateral Class I canine and molar relation was achieved with maximum intercuspation. The case was successfully managed by contemporary orthodontic technique with intra oral anchorage incorporated in archwire except the increased lower anterior facial height.

\section{Conclusion:}

Camouflage treatment of severe Class II malocclusion like this case in adolescents is challenging. Extractions of premolars, if undertaken after a thorough diagnosis leads to positive profile changes and an overall satisfactory facial aesthetics. A well chosen individualized treatment plan, undertaken with sound biomechanical principles and appropriate control of orthodontic mechanics to execute the plan is the surest way to achieve predictable results with minimal side effects. 


\section{References}

1. Hossain MZ et al, Prevalence of malocclusion and treatment facilities at Dhaka Dental College and Hospital. Journal of Oral Health, vol: 1, No. 1, 1994

2. Ahmed $\mathrm{N}$ et al, Prevalence of malocclusion and its aetiological factors. Journal of Oral Health, Vol. 2 No. 2 April 1996

3. Khan RS, Horrocks EN. A study of adult orthodontic patients and their treatment. Br J Orthod,18(3):183-194; 1991.

4. Salzmann JA. Practice of orthodontics. Philadelphia: J. B. Lippincott Company; p. 701-24;1966.

5. McNamara, J.A.: Components of Class II malocclusion in children 8-10 years of age, Angle Orthod, 51:177-202; 1981.

6. Case C S. The question of extraction in orthodontia. American Journal of Orthodontics, 50: 660-691; 1964.

7. Case C S. The extraction debate of 1911 by Case, Dewey, and Cryer. Discussion of Case: the question of extraction in orthodontia. American Journal of Orthodontics, 50: 900-912; 1964.

8. Tweed C. Indications for the extraction of teeth in orthodontic procedure. American Journal of Orthodontics 30: 405-428; 1944.

9. Staggers J A. A comparison of results of second molar and first premolar extraction treatment. American Journal of Orthodontics and Dentofacial Orthopedics, 98: 430-36; 1990.

10. Luecke P E, Johnston L E. The effect of maxillary first premolar extraction and incisor retraction on mandibular position: testing the central dogma of 'functional orthodontics'. American Journal of Orthodontics and Dentofacial Orthopedics, 101: 4-12; 1992.

11. Proffit W R, Phillips C, Douvartzidis N. A comparison of outcomes of orthodontic and surgical-orthodontic treatment of
Class II malocclusion in adults. American Journal of Orthodonticsand Dentofacial Orthopedics, 101: 556-565; 1992.

12. Paquette D E, Beattie J R, Johnston L E. A long-term comparison of non extraction and premolar extraction edgewise therapy in 'borderline' Class II patients. American Journal of Orthodontics and Dentofacial Orthopedics, 102:1-14; 1992.

13. Taner-Sar soy L, Darendeliler N. The influence of extraction treatment on craniofacial structures: evaluation according to two different factors. American Journal of Orthodontics and Dentofacial Orthopedics 115: 508-514; 1999.

14. Basciftci F A, Usumez S. Effects of extraction and non extraction treatment on Class I and Class II subjects, Angle Orthodontist 73: 36-42; 2003.

15. Cleall JF, Begole EA. Diagnosis and treatment of Class II Division 2 malocclusion. Angle Orthod 52:38-60; 1982.

16. Strang RHW. Tratado de ortodoncia. Buenos Aires: Editorial Bibliografica Argentina; 1957. p. 560-70, 657-71.

17. Bishara SE, Cummins DM, Jakobsen JR, Zaher AR. Dentofacial and soft tissue changes in Class II, Division 1 cases treated with and without extractions. Am J Orthod Dentofacial Orthop 107:28-37; 1995.

18. Rock WP. Treatment of Class II malocclusions with removable appliances. Part 4. Class II Division 2 treatment. $\mathrm{Br}$ Dent J 168:298-302; 1990.

19. Arvystas MG. Nonextraction treatment of Class II, Division 1 malocclusions. Am J Orthod 88:380-95; 1985.

20. Mihalik, C.A.; Proffit, W.R.; and Phillips, C.: Long-term followup of Class II adults treated with orthodontic camouflage: A comparison with orthognathic surgery outcomes, Am. J. Orthod. 123:266-278, 2003. 